\title{
A High Performance Three-Phase Telecom Supply Incorporating a HF Switched Mode Rectifier with a Phase Shifted PWM Controller
}

\author{
Arushi Shahani ${ }^{\dagger}$, Bhim Singh*, and Bhuvaneshwari G* \\ $\dagger$ Dept. of Electrical and Electronics Engineering, University Institute of Engineering and Technology, Panjab University, \\ Chandigarh, India \\ * Dept. of Electrical Engineering, Indian Institute of Technology Delhi, New Delhi, India
}

\begin{abstract}
Telecom supplies need to conform to low Total Harmonic Distortion (THD) and high Power Factor (PF) as per IEC 61000-3-2 and IEEE 519-1992 standards. These high rating power supplies use a three phase utility in which low THD and high PF are realized via various passive and active wave shaping schemes. In this paper, a new design for three phase telecom power supplies is presented with circuit parameter values optimized for high performance in terms of a low THD, high PF, low ripple and high line and load regulation using a suitable combination of various strategies. The performance of the power supply is validated by extensive simulations.
\end{abstract}

Key Words: High Power Telecom Supply, Low THD, Phase Shifted PWM, Three Phase Switched Mode Rectifier, Unity Power Factor

\section{INTRODUCTION}

The increased use of telecom systems have led to increased harmonic content being injected into the utility and a low power factor. Both of these are caused by the non linear load behavior of [1] conventional diode rectifiers. High THD (Total Harmonic Distortion) violates EMI while a low PF (Power Factor) [1] is undesirable in electrical utilities. Telecom supplies now have to conform to low THD and high PF as per IEC 61000-3-2 and IEEE 519-1992 standards [1]. Low power $(<2 \mathrm{~kW})$ supplies, usually employ single phase systems, while for high power (2 to $15 \mathrm{~kW}$ ) systems employ three phase systems [1]-[10].

Single phase systems invariably use active Power Factor Correction (PFC) schemes, in which by active switching and control (Switched Mode Rectifiers SMR) of the line current, the current is made to follow a sinusoidal reference (usually the mains refernce waveform) so that it mimics the line voltage. This acheives unity PF and reduces THD to low levels. Most of such schemes require detection of the line current so that it may be incorporated into the feedback loop. Converters operating at a high frequency provide the benefits of galvanic isolation, a smaller size transformer and filter components. Single phase systems with a $\mathrm{P}<1 \mathrm{~kW}$ have been reported which need line current detection [2], and which do not need

Manuscript received Nov. 16, 2009; revised Mar. 12, 2010

† Corresponding Author: arushi.shahani@gmail.com

Tel: +91-9915233293, Panjab University

* Dept of Electrical Eng., Indian Institute of Technology Delhi, India current detection [3]. By the incorporation of a suitable PI (Proportional and Integral) voltage controller scheme, good output voltage regulation has been reported in [4] and [5]. A single phase circuit with a phase shifted PWM with unity PF and a low THD in the context of a UPS has been reported in [6].

For higher power, three phase utility based supplies are used in most applications. Three phase systems offer six pulse rectifications that inherently have a low THD and high PF. In these systems, both the passive and active wave shaping schemes are used for improving power quality at the ac mains. Passive schemes are used for low power low cost applications that avoid costly and complex active circuitry and for very high power applications where it is difficult for active control components to meet the high ratings. The intermediate power range uses both passive and active schemes.

Among the three phase systems using passive schemes, the use of multi-pulse (12-18 pulse or higher) rectifiers [7] offers an inherent low THD and high PF. An 18 pulse converter using a passive scheme, having a PI voltage controller [9] for good line and load regulation has been reported for a $12 \mathrm{~kW}$ supply. Active control schemes have been reported [2]-[10] where each individual phase has active control corresponding to single phase systems schemes. They offer all the advantages mentioned for single phase systems with a reduced THD and near unity PF due to the inherent multi-pulse feature. Additionally, by connecting the output secondary windings of boost dc-dc converters in series, the currents in the three 
phases are equalized leading to balanced three phase currents.

In this paper a new design for a three phase ac mains fed supply for a $60 \mathrm{Vdc}$ and up to $300 \mathrm{~A}$ load is presented with circuit parameter values optimized for operation at high power (up to $18 \mathrm{~kW}$ ) from a three phase utility, using a combination of several techniques. The individual phases use a PS-PWM (phase shifted - pulse width modulation) SMR (switched mode rectifier) [6] scheme that yields a very low THD $(<4 \%)$ and near unity PF in the line currents of three phases. The series connection of converter secondary windings yields balanced three phase currents and galvanic isolation with the use of a light high frequency transformer, as in [9] and it provides 6 pulse rectification. Both of these together result in a smaller filter capacitor. A common PI controller at the output provides excellent line and load regulation. The design and operation of the proposed supply is validated by extensive simulations in MATLAB.

\section{BASIC WORKING OF A SMR PS-PWM CIRCUIT}

The circuit shown in Fig. 1 uses a diode rectifier at the AC mains, followed by a switched mode converter. It is supplied a rectified voltage $V_{R}$ and draws a current $I_{R}$ from the mains as per the switching scheme of the switches, and so it is called a Switched Mode Rectifier (SMR).

The input voltage $V_{R}$ to the boost converter is a diode bridge rectified voltage from the mains voltage $V_{L}$, feeding a series inductor $L_{1}$. This is followed by a dc-dc converter circuit feeding a HF transformer primary winding. The capacitor $C_{1}$ is not for reducing the ripple in $V_{R}$ rather, it reduces the harmonic reverse feed into the mains feeder lines, and so it is quite a small value. The converter switches T1, T2, T3 and $\mathrm{T} 4$ are suitably paralleled by free wheeling diodes $\left(D_{1}\right.$ through $D_{4}$ ). The switches in one mode called the "transfer mode" of operation take the rectified mains voltage at its input and creates an alternating voltage on the converter primary winding, where the induced voltage in the secondary winding is full-wave rectified and supplied to the load $\mathrm{R}$ and duly paralleled by the filter capacitor $C_{2}$ for reducing voltage ripple. In this mode, the value of inductor current $I_{R}$ reduces as the energy stored in the inductor is transferred to the load. In another mode, called the "storing mode," the primary winding is shorted by the switches storing the energy in the inductor, so that $I_{R}$ increases. By adjusting the timings of the "storing mode" and "transfer mode" the current $I_{R}$ can be shaped to be a sinusoidal waveform.

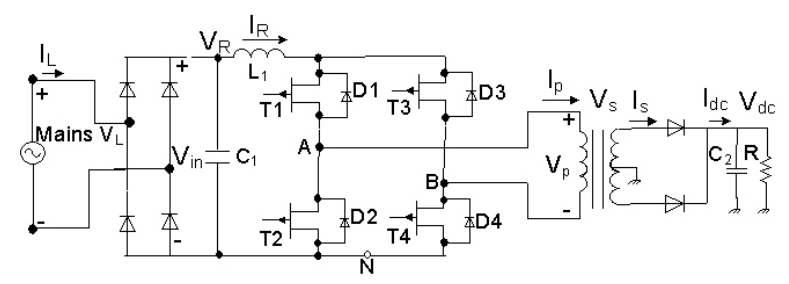

Fig. 1. Current Fed Boost Converter.

\section{A. Energy Transfer Mode}

In the "transfer mode" when the switches in cross locations i.e. $\mathrm{T} 1$ and $\mathrm{T} 4$ are $\mathrm{ON}(\mathrm{T} 1=\mathrm{T} 4=\operatorname{logic} 1)$ and the other two cross switches $\mathrm{T} 2$ and $\mathrm{T} 3$ are OFF $(\mathrm{T} 2=\mathrm{T} 3=$ logic 0 ), a polarity with top +ve in the primary winding as shown in Fig.2(c) is created. This transfer cycle is immediately succeeded by a "storing mode" cycle to be described in the next section. In the succeeding cycle, the switches $\mathrm{T} 2$ and $\mathrm{T} 3$ are $\mathrm{ON}$ while $\mathrm{T} 1$ and $\mathrm{T} 4$ are $\mathrm{OFF}$ to create a reverse polarity across the primary winding as shown in Fig. 2(e). The alternating voltage on the primary winding is "stepped down" in the secondary winding and full-wave rectified in the secondary winding circuit. In the transfer mode, voltage is induced in the secondary winding and the current flows in the secondary winding circuit feeding a current to the load R. This mode is called the "transfer mode," meaning that the energy is transferred from the primary winding to the secondary winding circuit. The energy is transferred from the inductor $L_{1}$ to $\mathrm{R}$, so that the inductor current $I_{R}$ reduces to a lower value.

The energy transferred to the load depends on the ON period of the cross switches when compared to the full cycle period. The ON period of ' $\mathrm{T} 1 \& \mathrm{~T} 4$ ' or ' $\mathrm{T} 2 \& \mathrm{~T} 3$ ' given by the "logic high" duration of $\mathrm{T}=\mathrm{T} 1 . \mathrm{T} 4+\mathrm{T} 2 . \mathrm{T} 3$ and is called the "transfer period" in the energy transfer mode. This period is variable and it is adjusted in the control scheme dynamically by comparing the reference and sensed dc voltages to offer good line and load regulation.

\section{B. Energy Storing Mode}

In this mode, in one cycle, the pair of switches in series say $\mathrm{T} 1 \& \mathrm{~T} 2$ in one path are turned $\mathrm{ON}$ while the corresponding pair of switches in the second path (T3 \& T4) are kept OFF as shown in Fig. 2(b). In another cycle, T3 \& T4 are ON while $\mathrm{T} 1 \& \mathrm{~T} 2$ are $\mathrm{OFF}$ as in Fig. 2(d). In this mode, the primary winding of the transformer is shorted by the switches, so that no energy is transferred to the secondary winding but instead the circuit in this mode allows the current $I_{R}$ to build in the inductor $L_{1}$ and thereby increases energy stored in the inductor. Therefore, this mode is called the "storing mode." Its duration is given by the "logic high" period of T2.T3 + T1.T2 which is the complement of T.

\section{Timing Sequence of Storing and Transfer Modes}

The gating scheme of the converter switches is such that the energy "storing" and "transfer" modes are activated alternately. The time period of the control pulses is kept constant. Part of the time period the inductor is "storing" energy while in the remaining part of the period the energy is transferred to the load. This cycle of alternating storing and transfer modes is shown in Fig.2 (b) through (e). The flow of the current is illustrated by dotted lines.

\section{PWM Signal Generation Scheme}

The circuit for generation of a control signal $V_{\text {control }}$ for PWM is shown in Fig. 3. The error $V_{e}$ between the reference dc voltage $V_{\text {set }}$ and the sensed dc voltage $V_{d c}$ is subjected 


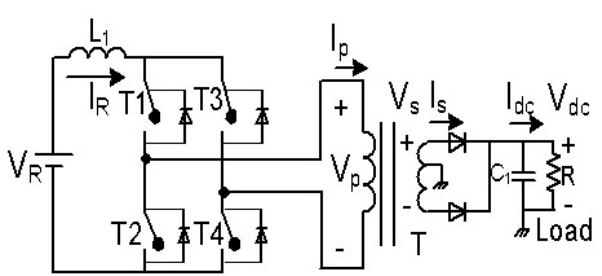

(a) Converter Schematic

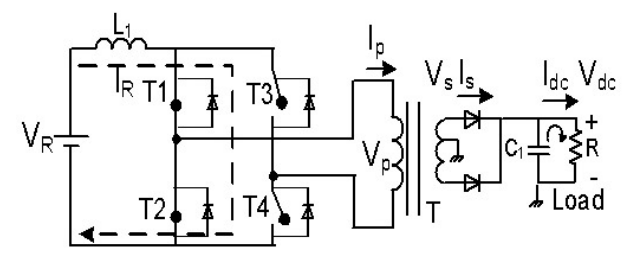

(b) Storing Mode(T1, T2-ON)

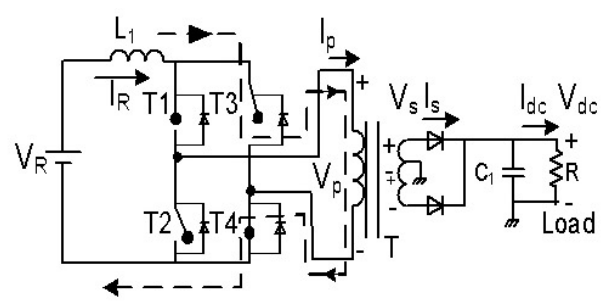

(c) Transfer Mode(T1, T4-ON)

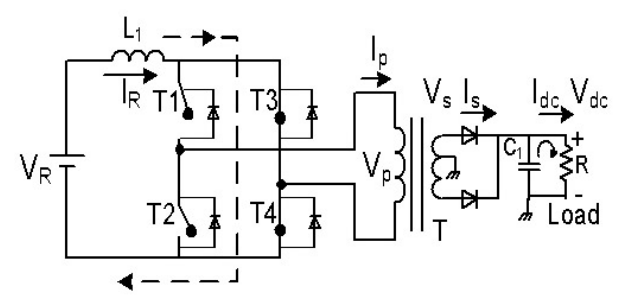

(d) Storing Mode(T4, T3-ON)

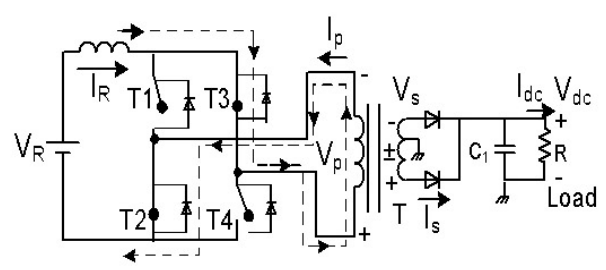

(e) Transfer Mode(T3, T2-ON)

Fig. 2. Converter using PS-PWM Control Scheme.

to a proportional and integral (PI) controller as shown in Fig. 3. This is multiplied by the reference ac voltage $V_{a c}$ ref (mains) voltage sampled from the line voltage so that the "total reference" signal contains the shape information of the mains voltage, and the output dc amplitude information from the PI controller signal. The sampled line current $I_{L}$ is then compared with the "total reference" and the net error signal between the two is amplified and constitutes the control signal $V_{\text {control }}$ that is then compared with a high frequency triangular wave to generate the PWM waveform P.

In the positive cycle of the current if:

$$
\begin{aligned}
& V_{\text {control }}>V_{\text {tri }}: \text { then } P=1 \\
& V_{\text {control }}<V_{\text {tri }}: \text { then } P=0 .
\end{aligned}
$$

Similarly, in negative cycle of the current if:

$$
\begin{aligned}
& V_{\text {control }}<V_{\text {tri }}: \text { then } P=1 \\
& V_{\text {control }}>V_{\text {tri }}: \text { then } P=0 .
\end{aligned}
$$

\section{E. Effects of the Energy Store and Transfer Mode Timings on the Rectifier Current Wave Shape and Output dc Voltage}

It can be seen form Fig. 4 that if the PWM P waveform "high" period is large, then the "storing mode" lasts longer than the "transfer time," so that the rectifier current $I_{R}$ increases in magnitude. For a smaller "high" time of $\mathrm{P}$, the storing time is less than the transfer time so that the inductor current will be reduced. For equal times of energy storing and energy transfer, the rectifier current will be constant. Thus by measuring the error between the line voltage normalized shape and the sensed rectified current shape and making the pulse width of PWM pulses P proportional to the amplified error, the storing and transfer times can be relatively adjusted to make the current shape follow the voltage shape. This causes a reduction in the THD and makes PF unity in the mains current. By making the amplitude of the sinusoidal shaped current proportional to the error between reference voltage $V_{\text {set }}$ and the sensed output voltage $V_{d c}$, good line and load regulation can be obtained. A PI control scheme is used in dc voltage error correction to give good regulation of the output dc voltage.

\section{PROPOSED THREE PHASE HIGH PERFORMANCE TELECOM SUPPLY}

The control circuit described above is extended to a three phase circuit [9] as in Fig. 5 except for the PI voltage controller, which being at the output, is common to the three phases. The control pulses T1-T4 generated in each phase drive the switches of their respective phase. A 50 $\mathrm{kHz}$ triangular wave is common to three phases. This supply configuration is shown in Fig. 5. The supply delivers a dc of $60 V_{d c}$, up to $300 \mathrm{~A}$ to the output load.

\section{PERFORMANCE OF THE CONVERTER}

The converter circuit has been optimized for its parameters namely $L_{1}, C_{1}, C_{2}$, and the integral and proportional controller gains $\mathrm{Ki}$ and $\mathrm{Kp}$ to give good regulation, low THD, low ripple, unity power factor etc. The main circuit components to be carefully chosen are $L_{1}$ and $C_{2}$, which have been selected by observing the performance of the converter over a range of values of $L_{1}, C_{2}$ and the converter frequency $F_{c}$. The nominal values of $L_{1}$ and $C_{2}$ have been arrived at assuming a lossless transfer of energy from the mains circuit to the load. Thereafter, the ripple and regulation performance has been simulated in a range of variations of $L_{1}$ and $C_{2}$ around the nominal values with due checks on the stability of the 


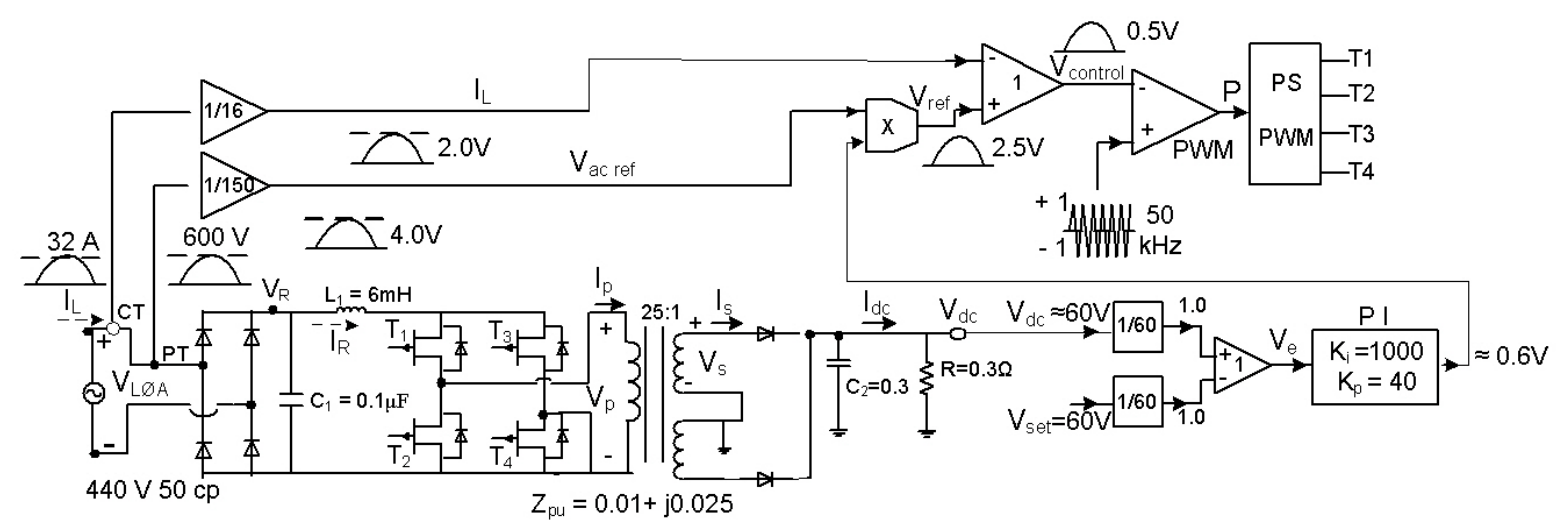

Fig. 3. Control Scheme and Generation of PWM.

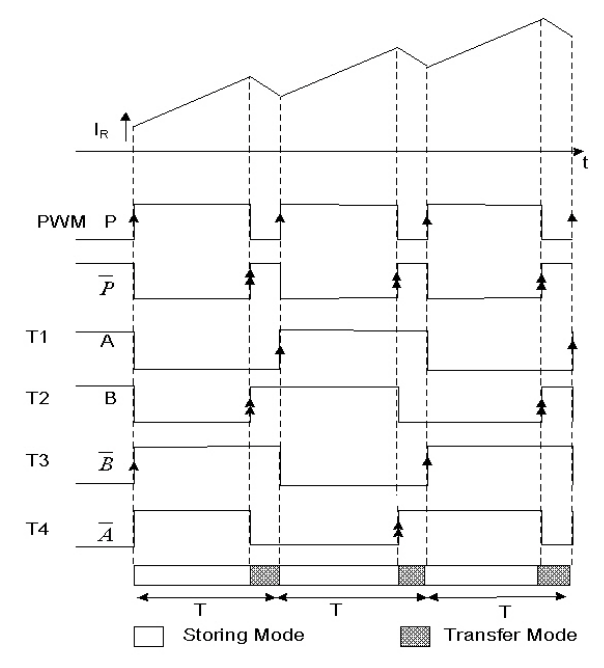

Fig. 4. Current Control via PS-PWM Scheme.

system. It has been observed that $L_{1}$ should be within 0.5 to $10 \mathrm{mH}$ for circuit stability. The THD and ripple performance are shown in Fig 6. The best performance is obtained for a value of $L_{1}$ that is in the 4 to $6 \mathrm{mH}$ range for frequencies $F_{c}$ between 5 to $50 \mathrm{kHz}$.

Similarly for $L_{1}=4 \mathrm{mH}$ a plot of the THD and ripple voltage vs the converter frequency in Fig. 7 shows that they are low for a frequency $F_{c}$ between 20 to $50 \mathrm{kHz}$.

In the same way, the capacitor $C_{2}$ is varied between 0.1 and $0.5 \mathrm{~F}$. It has been observed, as shown in Fig 8, that the circuit is stable and the THD is low for a capacitor $C_{2}$ that is between 0.2 and $0.7 \mathrm{~F}$. The smaller value of $0.3 \mathrm{~F}$ has been chosen in this paper.

Similarly, starting from the nominal values of $\mathrm{Ki}$ and $\mathrm{Kp}$ these have been fine tuned to give a low rise time and good regulation keeping track of stability. The optimized parameters of the proposed supply at $V_{d c}=60 \mathrm{~V}$ and $I_{d c}=200 \mathrm{~A}$ are given in Table I. G's refer to the attenuation of the sampled signals, in the control loop.
TABLE I

OPTIMIZED PARAMETERS VALUES

\begin{tabular}{|c|c|c|c|c|c|}
\hline \multicolumn{2}{|c|}{$\begin{array}{c}\text { Circuit } \\
\text { Parameters }\end{array}$} & \multicolumn{2}{|c|}{$\begin{array}{l}\text { Transformer } \\
\text { Parameters }\end{array}$} & \multicolumn{2}{|c|}{$\begin{array}{c}\text { Control } \\
\text { Parameters }\end{array}$} \\
\hline$\overline{L_{1}(m H)}$ & 6 & $R(m \Omega)$ & 3 & $\mathrm{Ki}$ & 1000 \\
\hline$C_{1}(u F)$ & 0.1 & $L(n H)$ & 10 & Kp & 40 \\
\hline$C_{2}(F)$ & 0.3 & $R m(k \Omega)$ & 10 & GLi & $1 / 16$ \\
\hline \multirow{4}{*}{$R(\Omega)$} & \multirow{4}{*}{0.3} & $L m(m H)$ & 100 & Grefy & $1 / 150$ \\
\hline & & $V \sec (V)$ & \multirow{3}{*}{40} & Gdc & $1 / 60$ \\
\hline & & & & Gpid & 1 \\
\hline & & Vpri $=2 \mathrm{kV}$ & & Gset & $1 / 60$ \\
\hline$V_{d c}$ & & $t_{c}=200 \mathrm{~A}$ & & $440 \mathrm{~V}$ & \\
\hline
\end{tabular}

\section{A. Waveforms in the Control Circuit}

For the converter circuit values and parameters of the control as per Table I, Fig. 9 shows the simulated waveforms in the converter circuit and control circuit.

The waveform $I_{R}$ is the rectified mains current in the inductor $L_{1}$, duly controlled by PWM. It is characterized by the linear rising and falling profile corresponding to the "storing" and "transfer" modes respectively. The succeeding set of waveforms are made up of the winding voltages and currents in the primary winding $V_{p}, I_{p}$ and the secondary winding $V_{s}, I_{s}$ of the dc-dc converter. The subscript A denotes that the converter is in phase A of the three phase circuit.

The waveform $\mathrm{P}$ is the PWM pulses that have been obtained by a comparison of $V_{\text {control }}$ and the $50 \mathrm{kHz}$ triangular wave. Derived from this comparison are the converter switch drive pulses T1 through T4.

1) Waveforms during the Transfer Mode: The waveform $\mathrm{T}$ is the transfer mode waveform:

$$
T=T 1 . T 4+T 2 . T 3 .
$$

When $\mathrm{T}=$ ' 1 ', the circuit is transferring energy to the load $\mathrm{R}$ ( $I_{R}$ is falling) and when it is ' 0 ' the energy is being stored in the inductor ( $I_{R}$ is rising).

In the transfer mode, if the primary winding and secondary winding voltage waveforms of the converter in phase $\mathrm{A}, V_{P \phi A}$, and $V_{S}$ are seen, then it is observed that they have a rectangular shape (voltage pulse) since for a short period of the converter switching, $V_{R}$ at input is constant. The corresponding current 


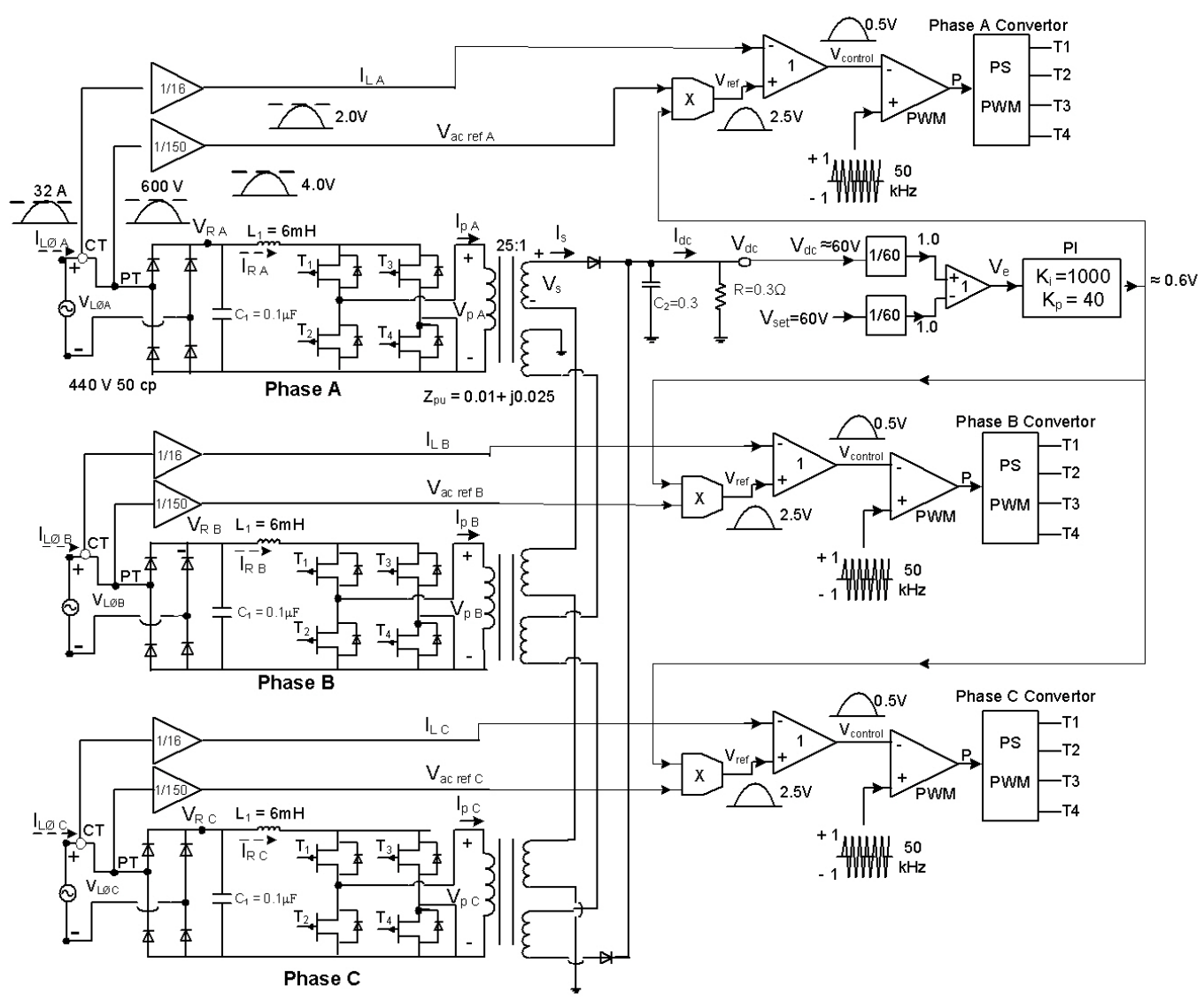

Fig. 5. Three Phase Circuit with PS-PWM Controlled SMR.

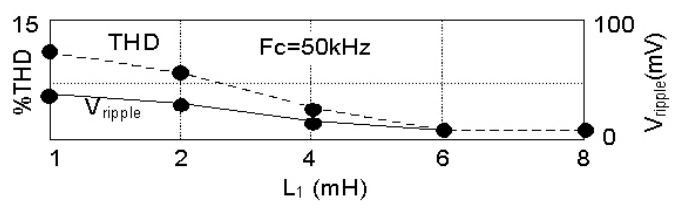

Fig. 6. THD and Ripple Voltage vs $L_{1}$.

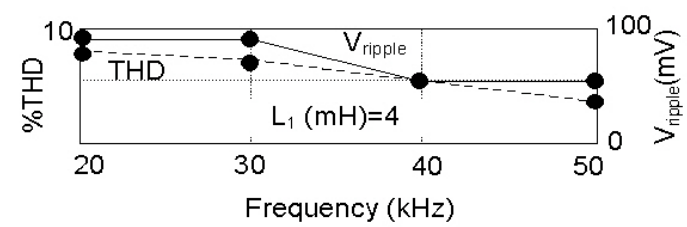

Fig. 7. THD and Ripple Voltage vs frequency $F_{c}$.

waveforms of the converter in phase $\mathrm{A}, I_{P \phi A}, I_{S}$ are observed (in converter) to have "rising" waveforms, since they are transferring power to the inductive load (transformer) under the action of a rectangular voltage pulse.

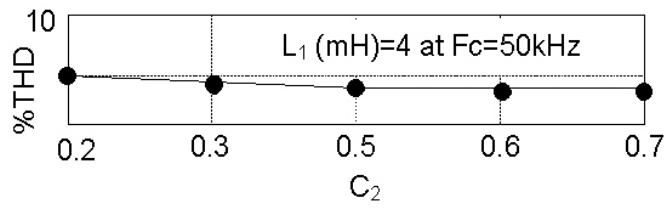

Fig. 8. THD vs Filter Capacitor.

The voltage pulse in the primary winding $V_{p}$ shows an upward kick at the end of each pulse which is due to the "reverse" current flow from the inductive transformer flowing into the freewheeling diodes or converter switches.

2) Waveforms during the Storing Mode: Since in the PSPWM scheme the "storing" and "transfer" modes alternate, the time period in which the 'transfer' (waveform) $\mathrm{T}$ is low, corresponds to the storing mode. In this period the inductor current $I_{R}$ increases in value linearly (energy is stored in the inductor $L_{1}$ ). Since in Fig. 9 the storing period is larger than transfer period, the overall value of $I_{R}$ increases in the waveform from left to right.

Further, since no transfer of the power to the load takes place in the converter during the storing period ('T1 AND T2' OR 'T3 AND T4' are ON shorting the primary winding), 


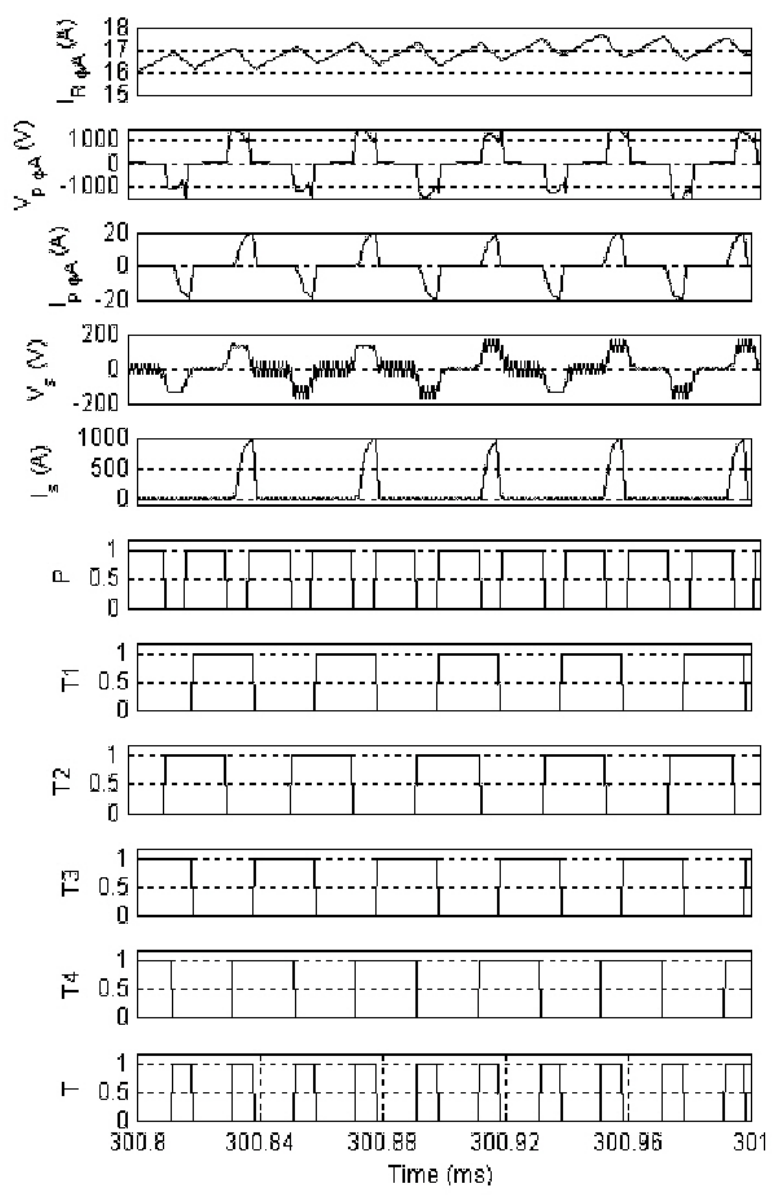

Fig. 9. Converter winding and Control Circuit Waveforms $\left(V_{d c}=60 \mathrm{~V}\right.$, $I_{d c}=200 A, V_{L}=440$ Vrms).

the waveforms in the primary and secondary windings have zero value in this period.

\section{B. Behavior of the Phase A, B and C Line Currents}

For the optimum values of the converter circuit parameters, given in Table I, the simulated waveforms of line currents in the three phases $\mathrm{A}, \mathrm{B}$, and $\mathrm{C}$ are shown in Fig 10. It can be seen that the line currents of phases $\mathrm{A}, \mathrm{B}$ and $\mathrm{C}\left(I_{L \phi A}\right.$, $I_{L \phi B}$ and $\left.I_{L \phi C}\right)$ are equal in magnitude and phase shifted by $120^{\circ}$ as balanced line currents. The THD in the line current is less than $4 \%$. Fig. 10 also shows the rectified voltage $V_{R}$ and current $I_{R}$ prior to the converter.

\section{Load and Line Regulation}

Fig. 11 and 12 show numerous simulated waveforms corresponding to the load current $I_{d c}=100 \mathrm{~A}$ and $300 \mathrm{~A}$. These waveforms show the transient as well as the steady state behavior of the voltages and currents at various nodes in the circuit.

In Fig. 13 and 14 the waveforms are given for the line voltage $V_{L}=390 \mathrm{~V}$ and $490 \mathrm{~V}$. The load and line regulation measured from expanded graph is $\approx 50 \mu \mathrm{V} / \mathrm{A}$ and $50 \mu \mathrm{V} / \mathrm{V}$.
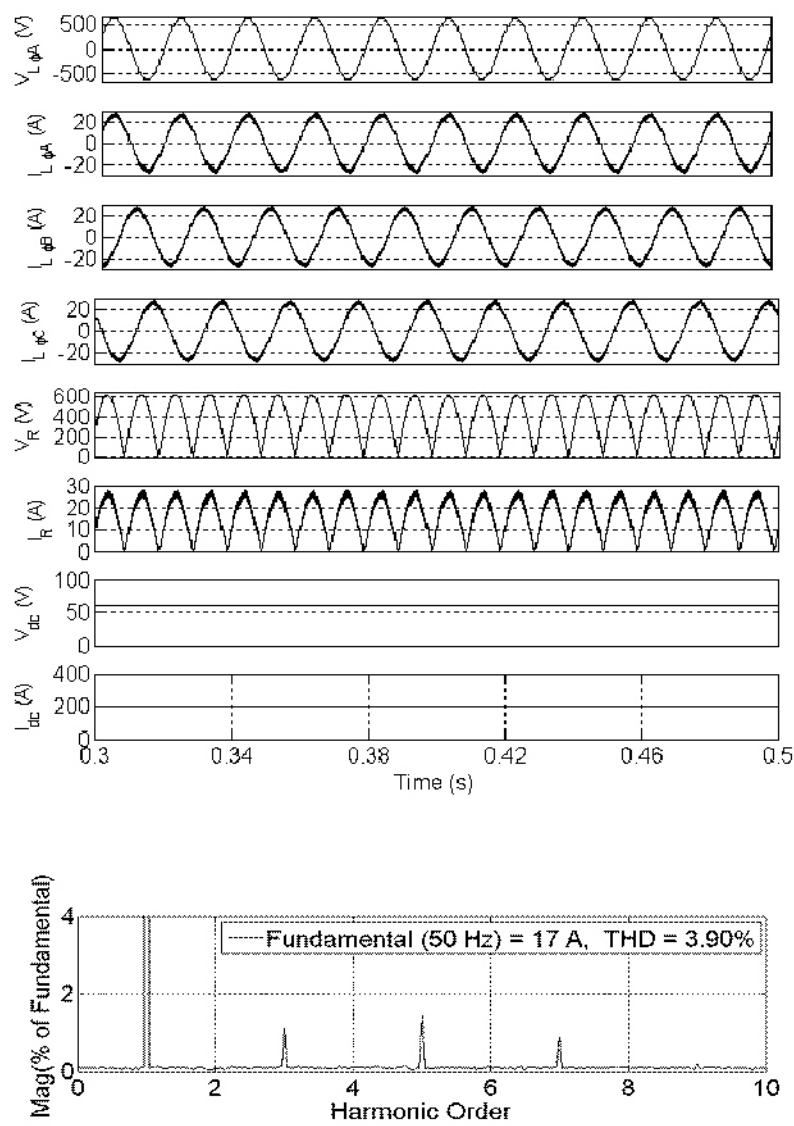

Fig. 10. Waveforms of converter at rated load $\left(V_{d c}=60 \mathrm{~V}, I_{d c}=200 \mathrm{~A}\right.$ $\left.V_{L}=440 \mathrm{~V}\right)$ voltage and currents in line, mains rectifier, output; and harmonic spectra.

\section{Total Harmonic Distortion}

Fig. 10 through 14 show the THD and harmonic spectra of the line current. It can be seen that the THD (as a percentage of the rms of the fundamental line current) varies between $7.45 \%$ to $3.65 \%$ being best in the optimized region of 300 A load and $440 \mathrm{~V}$ mains voltage. The percent of harmonic current for the first few harmonics in line $\mathrm{A}$ is also shown in these figures.

\section{E. Dynamic Performance}

The dynamic performance of the converter has been simulated by switching the load suddenly in the steady state. In Fig 15 , the load current is raised from $200 \mathrm{~A}$ to $300 \mathrm{~A}$ between 0.2 \& $0.4 \mathrm{sec}$. In Fig 16, the load current is switched from $300 \mathrm{~A}$ to $50 \mathrm{~A}$ between $0.2 \& 0.4 \mathrm{sec}$. In both cases the waveforms of the line current and output currents respond within a half cycle.

\section{CONCLUSIONS}

A new approach to high performance telecom supply design has been described and validated by MATLAB simulations. The use of a 3-phase supply has permitted the realization of a high power $18 \mathrm{~kW}, 60 V_{d c}$ supply with an $I_{d c}$ that is up to 300A. The use of a 3-phase ac mains supply lends 
soo

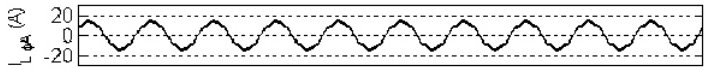

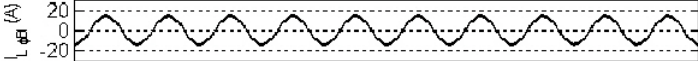

${ }_{-20}^{20} \sim \% \sim \sim \sim \sim \sim \sim \% \sim \%$

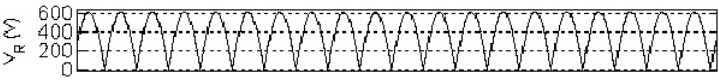
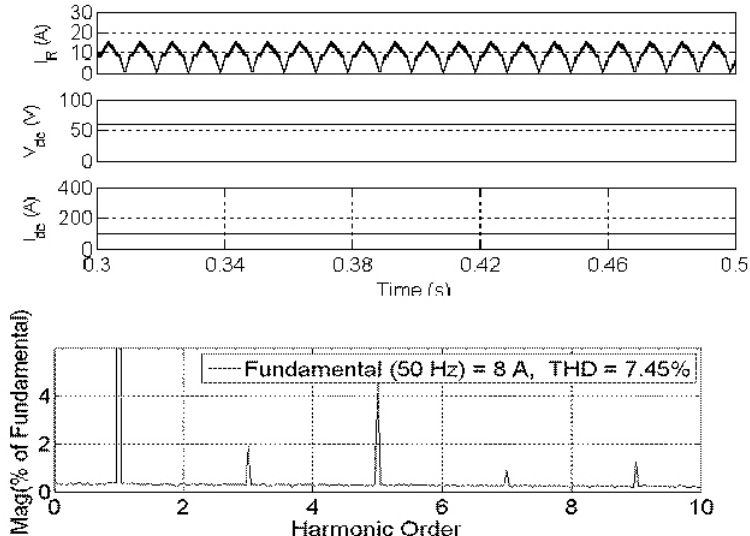

Fig. 11. Load regulation $\left(V_{L}=440 \mathrm{~V} I_{d c}=100 \mathrm{~A}\right)$ voltage and currents in line, mains rectifier, output; and harmonic spectra.
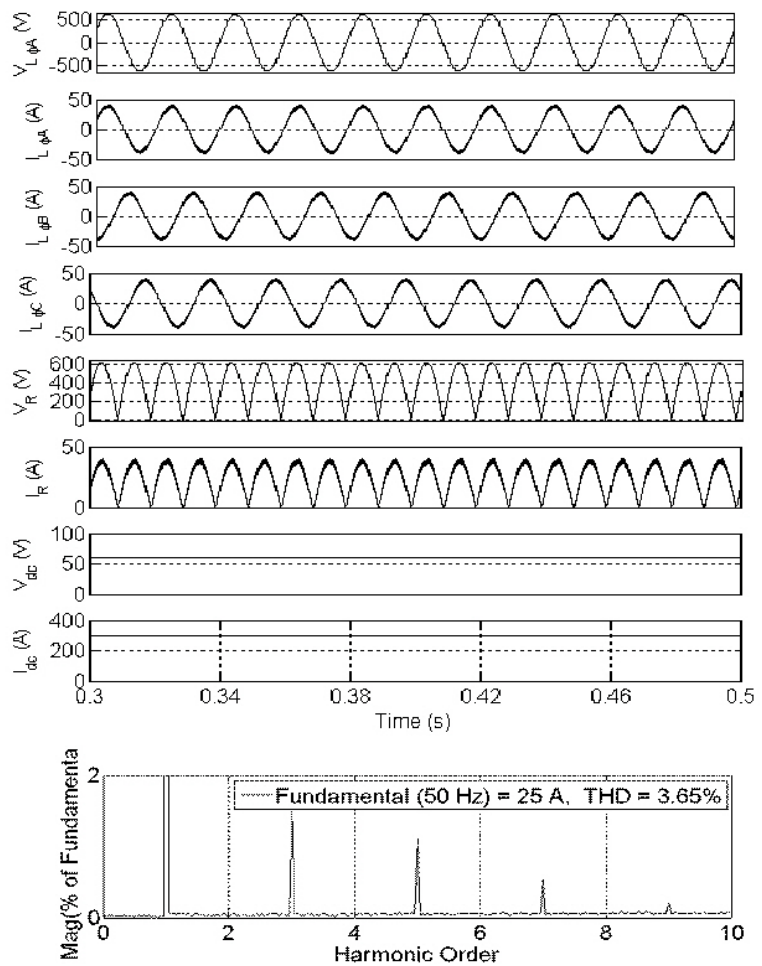

Fig. 12. Load regulation $\left(V_{L}=440 \mathrm{~V}, I_{d c}=300 A\right)$ voltage \& currents in line, mains rectifier, output; harmonic spectra.
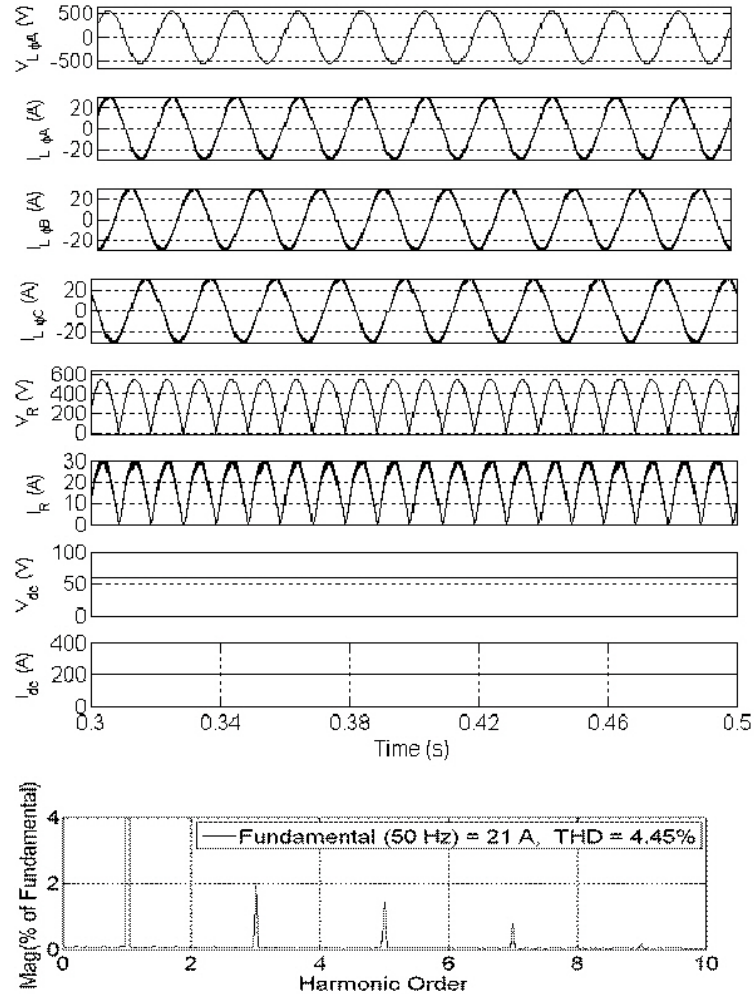

Fig. 13. Line regulation $\left(V_{L}=390 \mathrm{~V}, I_{d c}=200 \mathrm{~A}\right)$ voltage \& currents inline, mains rectifier, output; harmonic spectra.

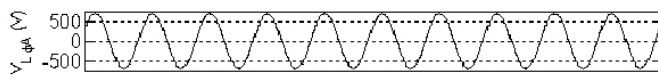

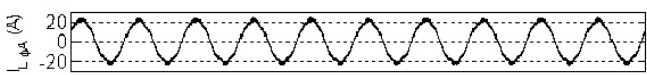

3:

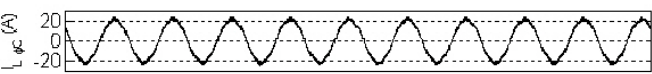

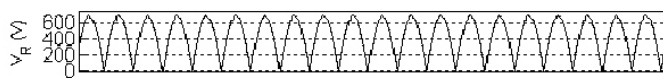
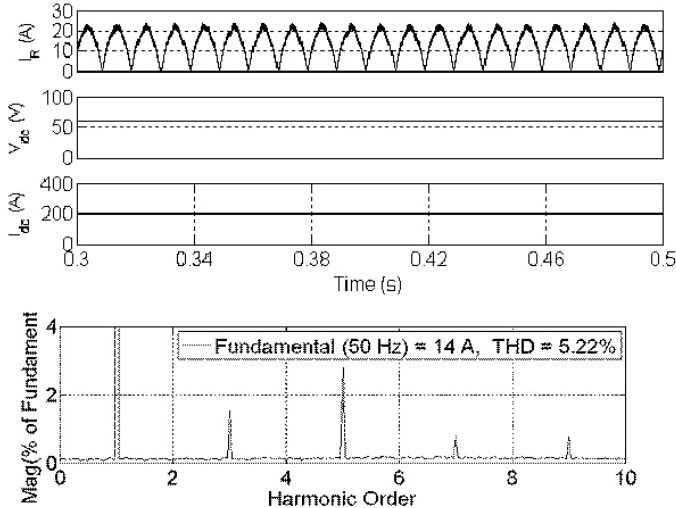

Fig. 14. Line regulation $\left(V_{L}=490 \mathrm{~V}, I_{d c}=200 \mathrm{~A}\right)$ voltage and currents in line, mains rectifier, output; and harmonic spectra. 


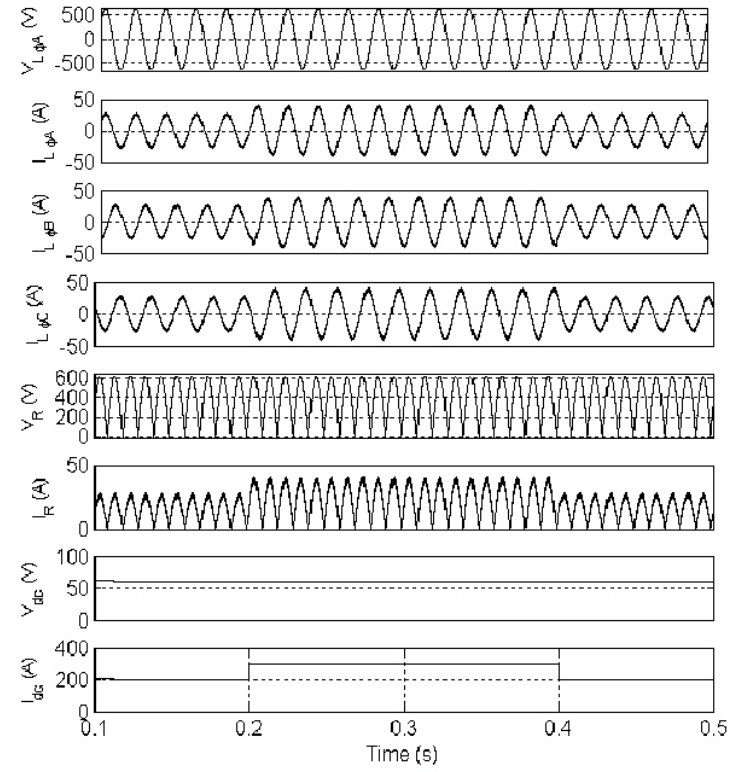

Fig. 15. Dynamic Performance. Load current changed from 200A to 300A.

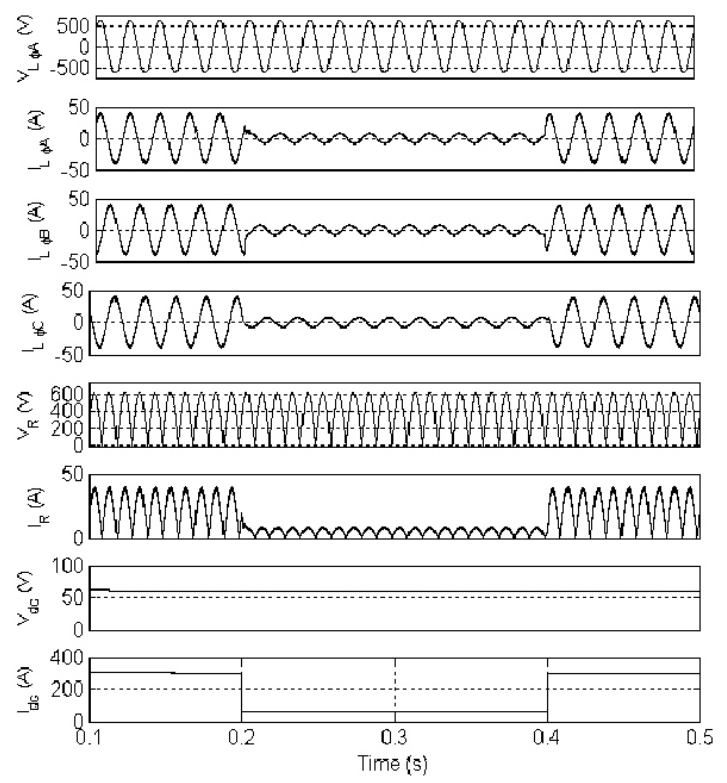

Fig. 16. Dynamic Performance. Load current changed from 300A to 50A.

itself to 6-pulse converters. This is achieved by connecting the converter's secondary windings from individual phases in series.

The technique of switched mode rectification SMR, and phase shifted PWM have been shown to give a sinusoidal line current with a unity power factor and a low THD. The PI voltage controller gives very good line and load regulation.

Extensive simulations have been carried out to give optimum values for the mains rectifier inductor $L_{1}$ and the output filter capacitor $C_{2}$. Similarly, other parameters have also been optimized carefully and these have been given in Table I. A summary of the performance features for the proposed circuit are given in Table II.

TABLE II

\section{SUMMARY OF KEY FEATURES}

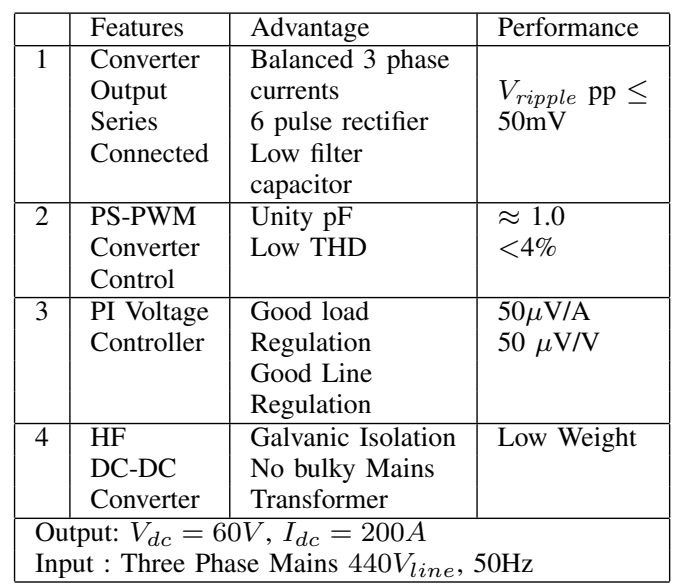

The advantages of the newly proposed circuit obtained by a combination of several ideas are summarized below:

Mains current is in phase with the voltage in each phase giving almost unity power factor.

Mains current is almost sinusoidal yielding a low total harmonic distortion.

Three phase circuit currents are balanced.

Galvanic isolation is provided by a compact high frequency converter transformer.

Final output dc is 6 pulse rectified exhibiting low ripple and using a smaller filter capacitor.

Load and line regulation are good.

\section{REFERENCES}

[1] Z Yang and P C Sen. "Recent developments in high power factor switch mode converters," in Proceedings of IEEE CCECE conference, pp. 477480, 1998.

[2] Bor-Ren Lin, "A novel PWM scheme for single-phase three-level powerfactor-correction circuit," IEEE Transactions on Industrial Electronics, Vol. 47, No.2, pp. 245-252, Apr. 2000.

[3] K. Hirachi and M. Nakoaka, "Circuit configuration of PFC converter and specific control implementation," Electronics Letters, Vol. 39, No. 16, pp. 1206-1207, 7 Aug. 2003.

[4] A Pandey, Bhim Singh and D P Kothari, "Comparative evaluation of single-phase unity power factor AC-DC boost converter topologies," Journal of the Institution of Engineers (India), Vol. 85, Pt. EL2, pp. 102-109 Sep. 2004.

[5] Kazunori Nishimura, Kastsuya Hirachi, Shinji Komiyama and Mutsuo Nakaoka, "Two buck choppers built-in single phase one stage PFC converter with reduced dc voltage ripple and its specific control scheme," in Proceedings of IEEE, Applied Power Electronics Conference, pp. 1378-1383, 2008.

[6] Katsuya Hirachi, Yasuhiro Arai, Junji Yoshitsugu, Laknath Gamage and Mutsuo Nakaoka, "A feasible high performance single-phase UPS incorporating switched mode rectifier with high frequency transformer link," in Proceedings of IEEE Power Electronics and Drive System, Vol. 2, pp. 792-797, 1997.

[7] F.J.M Seixas, "Generalization of the y-differential autotransformer for 12 and 18-pulse converters," Electric Power Systems Research, Vol. 76, No. 5, pp. 293-301, 2006.

[8] S Y R Hui, Y K E HO and H Chung, Y S lee, "Modular development of single stage 3-phase PFC using single phase step down converters," in Proceedings of IEEE Power Electronics Specialists Conferences, pp. 1965-1971, 1998. 
[9] F.J.M. Seixas and I. Barbi, "A $12 \mathrm{KW}$ three-phase low THD rectifier with high-frequency isolation and regulated DC output," IEEE Transactions Power Electronics, Vol. 19, No. 2, pp. 371-377, 2004.

[10] Brij N. Singh, Ambrish Chandra, Parviz Rastgoufard and KamalAl Haddad," "Single-phase switch mode boost rectifier: an improved design/control applied to three-phase AC-DC converters to power up telecommunication system," in Proceedings of IEEE Telecommunications Energy Conference, pp. 611-618, 2002.

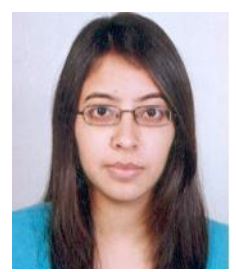

Arushi Shahani was born in Delhi, India, in 1988. She is currently pursuing her Bachelor of Engineering in Electrical and Electronics Engineering from the University Institute of Engineering and Technology, Chandigarh, India. She plans to pursue an advanced degree in the near future. She has interned at Bharat Electronics Limited and the Indian Institute of Technology Delhi. Her research interests include power electronics, control and micro sensors.

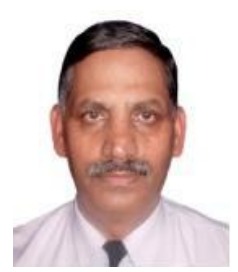

Bhim Singh (F'10, SM'99) was born in Rahamapur, India, in 1956. He received his B.E. in Electrical Engineering from the University of Roorkee, Roorkee, India, in 1977, and his M.Tech. and Ph.D. in Electrical Engineering from the Indian Institute of Technology (IIT) Delhi, New Delhi, India, in 1979 and 1983, respectively. In 1983, he joined the Department of Electrical Engineering, University of Roorkee, as a Lecturer, and in 1988, he became a Reader. In December 1990, he joined the Department of Electrical Engineering, IIT-Delhi, as an Assistant Professor and he became an Associate Professor in 1994 and a Professor in 1997. He received a Khosla Research Prize from the University of Roorkee in 1991. He was a recipient of JC Bose and Bimal K Bose awards from The
Institution of Electronics and Telecommunication Engineers (IETE) for his contribution in the field of Power Electronics in the year 2000. He was also a recipient of the Maharashtra State National Award of Indian Society for Technical Education (ISTE) in recognition of his outstanding research work in the area of Power Quality in the year 2006. He has received the PES Delhi Chapter Outstanding Engineer Award for the year 2006. He has been the General Chair of the IEEE International Conference on Power Electronics, Drives and Energy Systems (PEDES'2006) held in New Delhi. Dr. Singh is a Fellow of the Indian National Academy of Engineering (INAE), the National Academy of Science, India (NASI), the Institution of Engineers (India) (IE (I)), and the Institution of Electronics and Telecommunication Engineers (IETE). He is a Life Member of the Indian Society for Technical Education (ISTE), the System Society of India (SSI), and the National Institution of Quality and Reliability (NIQR). He is also a Fellow of the Institute of Electrical and Electronics Engineers (IEEE). His current research interests include power electronics, electrical machines and drives, active filters, flexible ac transmission systems (FACTS), high-voltage dc (HVDC), and power quality.

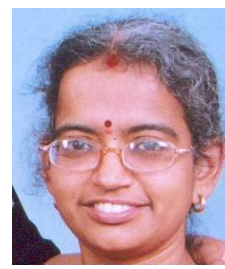

Bhuvaneshwari G obtained her master's and doctoral degrees from the Department of Electrical Engineering, Indian Institute of Technology (IIT) Madras, Madras, India. She was working as a faculty member in Anna University for about 2 years and subsequently she was with the electrical utility ComEd in Chicago, Illinois, USA. Since 1997, she has been working as a faculty member in the Department of Electrical Engineering, IIT, Delhi where she is now an Associate Professor. She is a Senior Member of IEEE and a Life Fellow of IETE. Her areas of interest are power electronics, electrical machines, drives and power quality. 